\title{
PREDIKSI LAPISAN AKUIFER DENGAN MENGGUNAKAN METODE SEISMIK REFRAKSI DI DESA JATIMULYO, KECAMATAN JATI AGUNG, LAMPUNG SELATAN
}

\section{AQUIFER LAYER PREDICTION USING SEISMIC REFRACTIONMETHOD}

\section{IN JATIMULYO VILLAGE, JATI AGUNG DISTRICT, SOUTH LAMPUNG}

\author{
Rhahmi Adni Pesma ${ }^{1^{*}}$, Mokhammad Puput Erlangga ${ }^{2}$, Intan Andiani Putri ${ }^{3}$, \\ Risky Martin Antosia ${ }^{4}$ \\ ${ }^{1234}$ Program Studi T. Geofisika, Jurusan Teknik M anufaktur dan M ineral Kebumian, Institut Teknologi \\ Sumatera
}

Received: 2020, $22^{\text {nd }}$ A pril Accepted: 2020, $05^{\text {th }}$ June

\section{Keyword:}

Seismic refraction; Resistivity;

Hagiwara method; Jatimulyo

\section{Corespondent Email: rhahmi.pesma@tg.itera.ac.id}

\section{H ow to cite this article: Pesma, R.A., Erlangga, M .P., Putri, I.A., \& Antosia, R.M . (2020). Prediksi Lapisan A kuifer M enggunakan M etode Seismik Refraksi Di Desa Jatimulyo, Kecamatan Jati Agung, Lampung Selatan. Jurnal Geofisika Eksplorasi, 6(2), 91-100.}

(c) 2020 JGE (Jurnal Geofisika Eksplorasi). This article is an open access article distributed under the terms and conditions of the Creative
Abstrak. Survei awal bawah permukaan untuk memprediksi lapisan akuifer sangat penting dilakukan agar terhindar dari posisi titik bor yang tidak potensial dan mendapatkan air tanah dengan debit yang tepat. Pada penelitian ini, prediksi lapisan akuifer dilakukan dengan menggunakan metode seismik refraksi di Desa Jatimulyo, Kecamatan Jati Agung, Kabupaten Lampung Selatan. Pengambilan data lapangan dilakukan pada tanggal 6 Oktober 2019 dengan menggunakan alat seismik SU M M IT X One dengan 24 Geofon. Data yang diperoleh berupa data first break waktu tempuh gelombang seismik yang kemudian diolah dan diinterpretasi dengan menggunakan metode Hagiwara. $\mathrm{H}$ asil pengolahan memperlihatkan tiga lapisan litologi bawah permukaan pada daerah penelitian. Lapisan pertama dengan kecepatan gelombang $360 \mathrm{~m} / \mathrm{s}$ merupakan lapisan lapuk (vegetal soil) pada kedalaman $2 \mathrm{~m}$ hingga $3.5 \mathrm{~m}$. Lapisan kedua dengan kecepatan gelombang 890 m/s merupakan pasir kering (dry sand) pada kedalaman $2 \mathrm{~m}$ sampai $8 \mathrm{~m}$. Lapisan ketiga dengan kecepatan gelombang $2300 \mathrm{~m} / \mathrm{s}$ merupakan campuran batuan lempung dan pasir yang tersaturasi air pada kedalaman lebih dari $8 \mathrm{~m}$. Sebagai data perbandingan, data sebaran resistivitas juga tersedia pada lintasan pengukuran yang sama di daerah penelitian. Hasil interpretasi secara keseluruhan memperlihatkan akuifer berada pada kedalaman sekitar $12 \mathrm{~m}$ dengan litologi batuan sedimen lempung tersaturasi sebagai zona target.

\begin{abstract}
An initial subsurface survey to predict the aquifer is important to avoid the unprospect drill location and getting groundwater with the right discharge. In this study, prediction of the aquifer was carried out using the seismic refraction method in Jatimulyo Village, Jati Agung District, South Lampung Regency. The data was collected on October 6, 2019 using the SUM MIT X One seismic tool with $24 \mathrm{G}$ eophones. The first break data from $p$-wave travel time is processed and interpreted using the Hagi wara method. Interpretation results show that there are three layers of subsurface lithology in the study area. The weathering layer was found at $2 \mathrm{~m}$ to $3.5 \mathrm{~m}$ depth with average velocity of $360 \mathrm{~m} / \mathrm{s}$. The second layer is dry sand with a velocity of $890 \mathrm{~m} / \mathrm{s}$ at a depth of $2 \mathrm{~m}$ to $8 \mathrm{~m}$. The third layer with a $2300 \mathrm{~m} / \mathrm{s}$ velocity is a mixture of clay rock and saturated sand at depths of more than $8 \mathrm{~m}$. As a comparison there is resistivity distribution data on the same
\end{abstract}



depth of $12 \mathrm{~m}$ with saturated clay sedimentary rock as a prospect of aquifer in this study area.

\section{PENDAHULUAN}

Pertambahan jumlah penduduk dan pembangunan disegala bidang khususnya di desa Jatimulyo Kabupaten Lampung Selatan, mengakibatkan pemanfaatan air tanah yang cenderung terus meningkat dari waktu ke waktu. Eksploitasi air tanah dapat dilakukan dengan pembuatan sumur gali untuk air tanah dangkal (air permukaan) atau melakukan pemboran sumur eksplorasi untuk air tanah dalam (lapisan akuifer). Pelaksanaan pemboran eksplorasi air tanah kadang menemui kegagalan dengan kata lain tidak mendapatkan air tanah dengan jumlah debit yang cukup, sehingga dana yang digunakan menjadi tidak tepat guna.

M asalah tersebut dapat diantisipasi dengan melakukan survei awal terlebih dahulu. Survei awal berguna untuk memprediksi keberadaan dan kedalaman lapisan akuifer serta mengetahui posisi titik bor potensial. Salah satu metode yang aplikatif untuk memprediksi lapisan akuifer adalah metode seismik refraksi.

Prediksi lapisan akuifer dengan metode seismik refraksi didasarkan pada sifat penjalaran gelombang yang mengalami refraksi dengan sudut kritis tertentu pada bidang batas yang memisahkan suatu lapisan dengan lapisan di bawahnya. Sumber gelombang yang dikirim akan akan menjalar ke dalam bumi, sedangkan energinya akan kembali ke permukaan yang kemudian ditangkap oleh serangkaian geofon yang dipasang di permukaan tanah dan disusun dalam lintasan lurus dengan sumber gelombang (Ali dkk., 2012).

Ada pun beberapa metode interpretasi dasar yang bisa digunakan dalam metode seismik refraksi, antara lain metode intercept time, waktu tunda (delay time) dan rekonstruksi muka gelombang (Raharjo, 2002)
Pada perkembangan lebih lanjut, dikenal beberapa metode lain, seperti metode $\mathrm{H}$ agiwara yang digunakan dalam penelitian ini. M etode Hagiwara merupakan pengembangan dari metode waktu tunda. Kelebihan dari metode ini adalah dapat menyajikan bentuk lapisan bawah permukaan mengikuti kontur bawah permukaan daerah pengukuran (Refrizon dkk., 2009).

Penelitian lain dengan tema penentuan kedalaman dan ketebalan akuifer menggunakan metode refraksi bias pada studi kasus Endapan Alluvial, South Dakotai, U nited States of A merica telah dilakukan oleh Listiyani dkk. (2006) yang berhasil memperkirakan akuifer pada lapisan yang tersusun dari batu napal pada kedalaman 0,28m-3,66 m.

Penentuan struktur bawah permukaan dengan menggunakan metode seismik refraksi di lapangan panas bumi Diwak dan Derekan, Kabupaten Semarang telah dilakukan oleh H udha dkk. (2014) yang secara umum dapat menunjukkan litologi bawah permukaan di dua daerah (Diwak dan Derek) penelitian dengan masing-masing terdapat dua lapisan. Penetrasi yang mampu direkam pada penelitian tersebut sebesar 0,75-9,16 m.

Adapun tujuan penelitian ini adalah memprediksi lapisan akuifer pada Desa Jatimulyo, Kabupaten Lampung Selatan dengan menggunakan metode seismik refraksi prinsip Hagiwara.

\section{TINJAUAN PUSTAKA}

Gelombang seismik adalah gelombang elastik yang merambat dalam bumi. Bumi sebagai medium gelombang terdiri dari beberapa lapisan batuan yang antar satu lapisan dengan lapisan lainnya mempunyai sifat fisis yang berbeda. Ketidak-kontinuan sifat medium ini menyebabkan gelombang 
seismik yang merambatkan sebagian energinya dan akan dipantulkan serta sebagian energi lainnya akan diteruskan ke medium di bawahnya (Telford dkk., 1990)

Metode seismik merupakan salah satu metode yang sangat penting dan banyak dipakai di dalam teknik geofisika. Hal ini disebabkan metode seismik mempunyai ketepatan serta resolusi yang tinggi di dalam memodelkan struktur geologi di bawah permukaan bumi. Dalam menentukan struktur geologi, metode seismik dikategorikan ke dalam dua bagian yang besar yaitu seismik bias dangkal (head wave or refrected seismic) dan seismik refleksi (reflected seismic). Seismik refraksi efektif digunakan untuk penentuan struktur geologi yang dangkal sedang seismik refleksi untuk struktur geologi yang dalam (Nurdiyanto dkk., 2011).

Keterbatasan metode seismik refraksi adalah tidak dapat dipergunakan pada daerah dengan kondisi geologi yang terlalu kompleks. Metode ini telah dipergunakan untuk mendeteksi perlapisan dangkal dan hasilnya cukup memuaskan. Menurut Sismanto, sebagaimana dikutip oleh Sri dan Supriyadi (2014), asumsi dasar yang harus dipenuhi untuk penelitian perlapisan dangkal adalah:

a. Medium bumi dianggap berlapis-lapis dan setiap lapisan menjalarkan gelombang seismik dengan kecepatan yang berbeda.

b. Semakin bertambah kedalaman, lapisan batuan akan semakin kompak.

c. Panjang gelombang seismik lebih kecil daripada ketebalan lapisan bumi.

d. Perambatan gelombang seismik dapat dipandang sebagai sinar, sehingga mematuhi hukum - hukum dasar lintasan.

e. Pada bidang batas antar lapisan, gelombang seismik merambat dengan kecepatan pada lapisan dibawahnya. f. Kecepatan gelombang bertambah dengan bertambahnya kedalaman yang dapat dilihat pada Gambar 1.

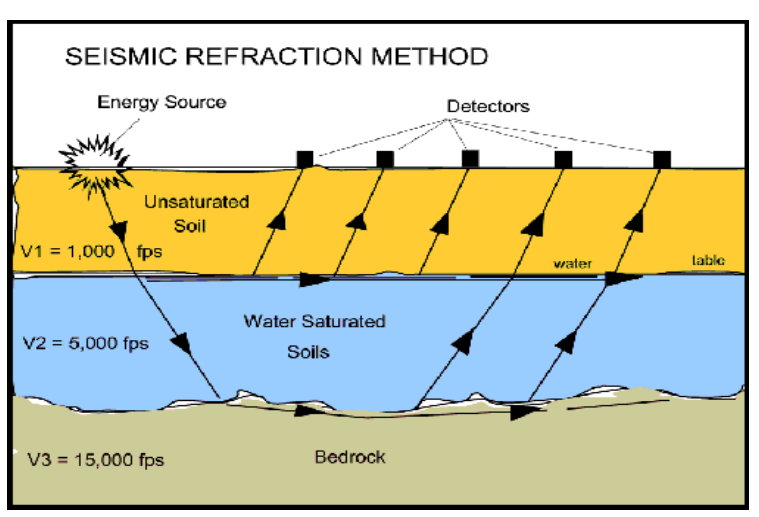

Gambar 1. Penjalaran gelombang seismik refraksi pada bidang batas lapisan

Secara umum hasil dari suatu survei geofisika adalah membuat interpretasi pengolahan data bawah permukaan secara akurat. Data-data waktu dan jarak dari kurva travel time diterjemahkan menjadi suatu penampang geofisika dan akhirnya dijadikan penampang geologi. Secara umum metode interpretasi seismik refraksi dapat dikelompokkan menjadi tiga kelompok utama, yaitu intercept time, delay time method dan wafe front method.

Salah satu metode perhitungan waktu tiba gelombang seismik untuk mencerminkan lapisan bawah permukaan adalah Metode Hagiwara. Metode ini merupakan metode waktu tunda yang berdasarkan asumsi bahwa undulasi bawah permukaan tidak terlalu besar. Kelebihan dari metode Hagiwara adalah lapisan bawah permukaan dapat ditampilkan mengikuti kontur bawah permukaan itu. Berbeda dengan metode intercept time yang menganggap lapisan dibawah permuaan adalah flat (bidang). Terutama untuk lapisan bawah permukaan yang harus detail, maka metode $\mathrm{H}$ agiwara adalah metode perhitungan yang menjadi pilihan utama (Refrizon, dkk., 2009). 
Perhitungan dengan metode Hagiwara dikembangkan untuk struktur bawah permukaan yang terdiri dari dua lapisan atau lebih. Bidang batas lapisan yang akan diperlihatkan oleh hasil perhitungan merupakan rata-rata kedalaman yang memiliki kerapatan yang berbeda. Bila kerapatan berbeda maka kecepatan gelombang seismiknya juga akan berbeda, sehingga arah penjalaran gelombang seismik akan mengalami pembiasaan.

Bila dinotasikan waktu perambatan gelombang bias dari titik tembak $A$ ke titik penerima $P$ dengan $T A P$, waktu perambatan dari $B$ ke $P$ dengan $T B P$ dan waktu perambatan dari $A$ ke $B$ dengan $T A B$. $T T^{\prime} A P$ ditunjukkan oleh persamaan :

$T^{\prime} A P=T A P-\frac{(T A P+T B P-T A B)}{2}$

$T^{\prime} A P=\frac{h_{A} \cos i}{v_{1}}+\frac{x}{v_{2}}$

Pada Persamaan 1, $T^{\prime} A P$ adalah linier terhadap $x$. Jika diambil $x$ sebagai absis dan $T^{\prime} A P$ sebagai ordinat dan diplot titik-titik yang bersesuaian, maka garis lurus tersebut merupakan suatu short (bentuk baru yang lebih pendek) dari kurva travel time yang dikandung oleh titik-titik yang berhubungan. Nilai $T^{\prime} A P$ dengan mudah dapat dihitung dari Persamaan 2 dan kecepatan $\mathrm{V}_{2}$ pada lapisan bawah diperolah dari kemiringan (slope) garis lurus. $T^{\prime} A P$ yang diperoleh dari Persamaan 1 merupakan suatu besaran yang menunjukkan kecepatan pada lapisan bawah (velocity travel-time). Dengan cara yang sama dapat diperoleh:

$T^{\prime} B P=T B P-\frac{(T A P+T B P-T A B)}{2}$

Bila jarak ke titik penerima adalah $x$, dengan mengambil titik $B$ sebagai titik asal (referensi) maka diperoleh :
$T^{\prime} B P=\frac{h_{B} \cos i}{v_{1}}+\frac{x}{v_{2}}$

dengan kedalaman lapisan pada titik A $\left(h_{A}\right)$ dan pada titik $\mathrm{B}\left(h_{B}\right)$.

Dalam Persamaan 4, $v_{1}$ dapat diperoleh dari kurva travel-time dari gelombang langsung dekat titik tembak. $T A P, T B P$ dan $T A B$ diperoleh dengan cara observasi. Tetapi $\cos i$ tidak dapar dicari, karena $v_{2}$ biasanya tidak diketahui. Jika harga $v_{2}$ dapat diketahui, kedalaman $h p$ dan titik penerima $\mathrm{P}$ dapat diperoleh dari :

$h_{p}=\frac{v_{1}}{2 \cos i}(T A P+T B P-T A B)$

Harga dari $T^{\prime} A P$ atau $T^{\prime} B P$ yang berhubungan dengan $T A P$ atau $T B P$ dapat dibaca dari ektensi (memperpanjang) kurva $T^{\prime} A P$ atau $T^{\prime} B P$. Jadi harga kedalaman $h_{p}$ dapat dihitung dari Persamaan 6 atau

Persamaan 7 berikut :

$h_{p}=\frac{v_{1}}{2 \cos i}\left(T A P-T^{\prime} A P\right)$

atau

$h_{p}=\frac{v_{1}}{2 \cos i}\left(T A P-T^{\prime} B P\right)$

\section{METODE PENELITIAN}

Lokasi akuisisi berada di belakang perumahan subsidi Green Jatimulyo 2, Desa Jatimulyo, Kecamatan Jati Agung, Kabupaten Lampung Selatan yang dapat dilihat pada Gambar 2. A kuisisi data dilaksanakan pada tanggal 6 Oktober 2019. M etode yang digunakan pada penelitian ini adalah metode seismik refraksi yang memiliki panjang lintasan pengukuran 50 meter. Jarak antar penerima gelombang seismik (geofon) adalah 2 meter, sedangkan jarak tembakan terdekat terhadap geofon terdekat maupun terjauh adalah 2 meter. D esain akuisisi seismik refraksi 
dapat dilihat pada Gambar 3. Berdasarkan posisi, tembakan dilakukan sebanyak tiga kali penembakan (shot) atau pengambilan data. Kemudian pada saat pengolahan data, ketiga data tersebut untuk setiap posisi tembakan akan dijumlahkan kemudian dirata-ratakan. $\mathrm{Hal}$ ini bertujuan agar data yang dihasilkan untuk setiap posisi tembakan memiliki kualitas yang bagus.

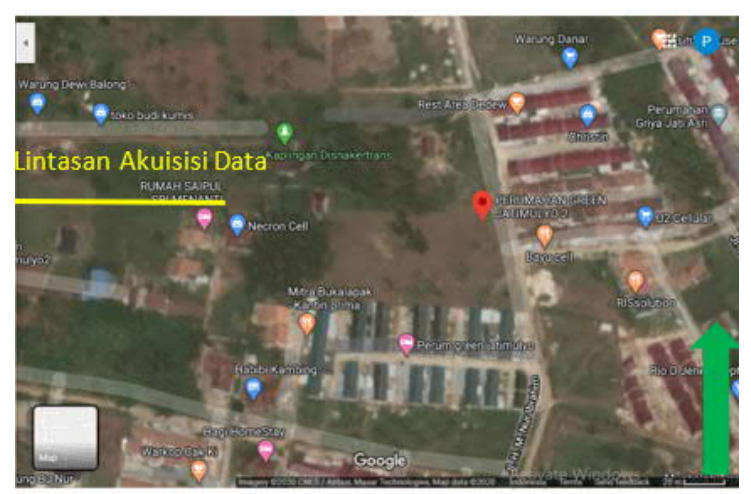

Gambar 2. Orientasi lintasan akuisisi data pada lokasi penelitian

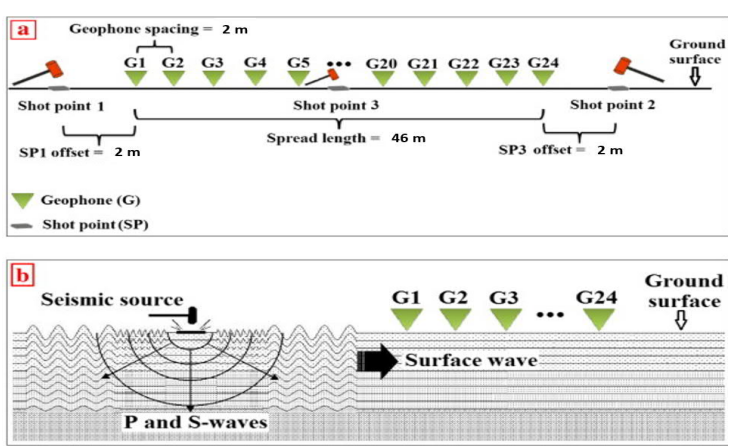

Gambar 3. (a) Desain akuisisi gelombang seismik refraksi (b) Penggambaran fenomena penjalaran gelombang di bawah permukaan

\section{HASIL DAN PEMBAHASAN}

Dari data lapangan maka didapatkan data first break waktu tempuh gelombang seismik yang dapat dilihat pada Tabel 1. Data tersebut memperlihatkan bawah ketika poisis geofon semakin menjauh dari posisi tembakan, maka nilai tiba gelombang refraksinya semakin membesar. $\mathrm{H}$ al ini disebabkan karena lintasan yang ditempuh gelombang dari sumber ke penerima semakin jauh. Data tersebut juga dibuatkan kurva waktu tiba gelombang terhadap posisi geofon yang dapat dilihat pada Gambar 4.

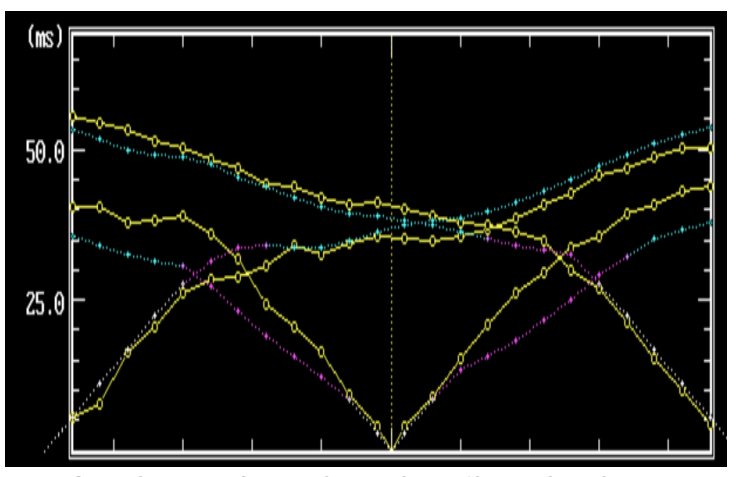

Gambar 4. Crossplot waktu tiba gelombang terhadap posisi geofon

Perhitungan kecepatan gelombang seismik dari setiap refraktor dapat dihitung dari kurva waktu tiba gelombang tersebut. A khirnya juga bisa dihitung kedalaman refraktor di bawah setiap geofon. Kecepatan gelombang seismik dari setiap medium dapat dihitung berdasarkan gradien (kemiringan) kurva yang dihasilkan. Semakin tinggi nilai gradien yang dimiliki kurva tersebut maka nilai kecepatan gelombang seismik pada lapisan bumi semakin rendah. Begitu juga sebaliknya, untuk kedalaman refraktor di bawah setiap geofon dihitung dengan menggunakan prinsip Hagiwara dimana proses perhitungan akan melihat selisih waktu tiba gelombang dari arah yang berlawanan.

Hasil pengolahan data seismik refraksi dengan metode Hagiwara dalam penelitian ini memperoleh tiga lapisan di bawah permukaan. Lapisan pertama memiliki nilai kecepatan gelombang $360 \mathrm{~m} / \mathrm{s}$, lapisan kedua memiliki nilai kecepatan gelombang $890 \mathrm{~m} / \mathrm{s}$, sedangkan pada lapisan kedua memiliki kecepatan gelombang $2300 \mathrm{~m} / \mathrm{s}$ yang dapat dilihat pada Gambar 5. Merujuk pada nilai kecepatan gelombang seismik untuk setiap batuan (Gary M avko, 1998) yang dapat dilihat pada Tabel 2, maka lapisan pertama merupakan lapisan lapuk (vegetal soil). Lapisan lapuk ini memiliki rentang kecepatan $300 \mathrm{~m} / \mathrm{s}$ - $700 \mathrm{~m} / \mathrm{s}$ dan berada pada kedalaman 2 - 3,5 meter dari 
permukaan. Lapisan ini juga memiliki nilai permeabilitas yang tinggi karena bersifat lapuk. Pada lapisan kedua dimana kecepatan gelombang seismiknya adalah $890 \mathrm{~m} / \mathrm{s}$ merupakan pasir kering (dry sand). Pasir kering memiliki rentang kecepatan $400 \mathrm{~m} / \mathrm{s}$ $1200 \mathrm{~m} / \mathrm{s}$. Lapisan ini memiliki rentang kedalaman dari 2 - 3,5 meter sampai 8 - 10 meter terhadap permukaan. Nilai permeabilitas pada lapisan ini lebih rendah dibandingkan lapisan pertama. Pada lapisan ketiga merupakan campuran antara batuan lempung dan pasir yang tersaturasi air (saturated sandy clay). Pada lapisan ketiga ini terdapat kandungan air. Lapisan ini berada pada kedalaman 8 - 10 meter lebih. Nilai kecepatan gelombang seismik pada lapisan ini adalah $2300 \mathrm{~m} / \mathrm{s}$. Nilai kecepatan ini berada di dalam rentang kecepatan seismik pada batuan lempung tersaturasi $(1100 \mathrm{~m} / \mathrm{s}-2500 \mathrm{~m} / \mathrm{s})$ dan batuan pasir berpori dan tersaturasi $(2000 \mathrm{~m} / \mathrm{s}$ - $3500 \mathrm{~m} / \mathrm{s}$ ). Model bawah permukaan ini dapat dilihat pada Gambar 6 .

Tabel 1. Hasil picking first break dari waktu tempuh penjalaran gelombang.

\begin{tabular}{cccccccc}
\hline Geophone & Position & \multicolumn{2}{c}{ Shot $=50 \mathrm{~m}$} & \multicolumn{2}{c}{ Shot $=25 \mathrm{~m}$} & \multicolumn{2}{c}{ Shot $=0 \mathrm{~m}$} \\
\cline { 3 - 7 } Shot near & 0 & $\mathrm{~ms}$ & $\mathrm{~S}$ & $\mathrm{~ms}$ & $\mathrm{~S}$ & $\mathrm{~ms}$ & $\mathrm{~S}$ \\
\hline 1 & 2 & 55,4 & 0,0554 & 40,6 & 0,0406 & 5,4 & 0,0054 \\
2 & 4 & 54,4 & 0,0544 & 40,5 & 0,0405 & 7,9 & 0,0079 \\
3 & 6 & 53,2 & 0,0532 & 37,7 & 0,0377 & 16,5 & 0,0165 \\
4 & 8 & 51,4 & 0,0514 & 38,3 & 0,0383 & 20,6 & 0,0206 \\
5 & 10 & 50,4 & 0,0504 & 39 & 0,039 & 26 & 0,026 \\
6 & 12 & 48,5 & 0,0485 & 35,8 & 0,0358 & 28,5 & 0,0285 \\
7 & 14 & 46,9 & 0,0469 & 31,7 & 0,0317 & 28,8 & 0,0288 \\
8 & 16 & 44,3 & 0,0443 & 24,4 & 0,0244 & 30,7 & 0,0307 \\
9 & 18 & 44 & 0,044 & 20,6 & 0,0206 & 34,2 & 0,0342 \\
10 & 20 & 42,1 & 0,0421 & 16,2 & 0,0162 & 32,6 & 0,0326 \\
11 & 22 & 40,9 & 0,0409 & 9,2 & 0,0092 & 34,5 & 0,0345 \\
12 & 24 & 41,2 & 0,0412 & 4,1 & 0,0041 & 35,5 & 0,0355 \\
13 & 26 & 39,9 & 0,0399 & 4,1 & 0,0041 & 35,2 & 0,0352 \\
14 & 28 & 39 & 0,039 & 8,9 & 0,0089 & 34,8 & 0,0348 \\
15 & 30 & 38 & 0,038 & 15,2 & 0,0152 & 35,5 & 0,0355 \\
16 & 32 & 37,4 & 0,0374 & 20,9 & 0,0209 & 36,7 & 0,0367 \\
17 & 34 & 36,4 & 0,0364 & 26 & 0,026 & 38,6 & 0,0386 \\
18 & 36 & 34,8 & 0,0348 & 29,5 & 0,0295 & 41 & 0,041 \\
19 & 38 & 29,8 & 0,0298 & 33,6 & 0,0336 & 42,8 & 0,0428 \\
20 & 40 & 26,9 & 0,0269 & 35,5 & 0,0355 & 45,9 & 0,0459 \\
21 & 42 & 21,2 & 0,0212 & 39,3 & 0,0393 & 46,9 & 0,0469 \\
22 & 44 & 15,2 & 0,0152 & 40,9 & 0,0409 & 48,7 & 0,0487 \\
23 & 46 & 9,8 & 0,0098 & 43,1 & 0,0431 & 50,4 & 0,0504 \\
24 & 48 & 4,4 & 0,0044 & 44 & 0,044 & 50,4 & 0,0504 \\
Shot faryyyyyyy (East) & 50 & 0 & 0 & & & &
\end{tabular}

Selain menggunakan hasil pengolahan data seismik refraksi, dalam penelitian ini juga menggunakan data pembanding berupa data sebaran resistivitas hasil pengukuran dengan metode geolistrik pada garis pengukuran yang sama di lokasi tersebut yang dapat dilihat pada Gambar 7. Agar lebih mudah dalam menginterpretasikan struktur lapisan bawah permukaan maka hasil pencitraan dengan metoe seismik refraksi dapat disatukan dengan 
hasil pencitraan metode geolistrik seperti pada

Gambar 8. Dari penggabungan tersebut, maka lapisan pertama dengan ketebalan 0 - 3,5 meter tidak dapat terlihat nilai resistivitasnya. $\mathrm{Hal}$ ini disebabkan karena sebaran titik resistivitasnya minimal baru dapat ditampilkan pada kedalaman 3,5 meter. Pada lapisan kedua memiliki rentang resistivitas 148 - $390 \Omega \mathrm{m}$, berdasarkan nilai resistivitas pada batuan yang dapat dilihat pada Tabel 3, maka lapisan ini berupa batu pasir murni (fine sand). Nilai rentang resistivitas lapisan kedua berkisar 48,8 - $148 \Omega \mathrm{m}$, dengan perkiraan berupa batu lempung pasiran (sandy clay). Pada lapisan ketiga juga terdapat dua rentang nilai resistivitas, yaitu 6,1 - $37 \quad \Omega \mathrm{m}$ yang diperkirakan batuan lempung tersaturasi dan 37 - $150 \Omega \mathrm{m}$ berupa lempung pasiran yang tersaturasi air.

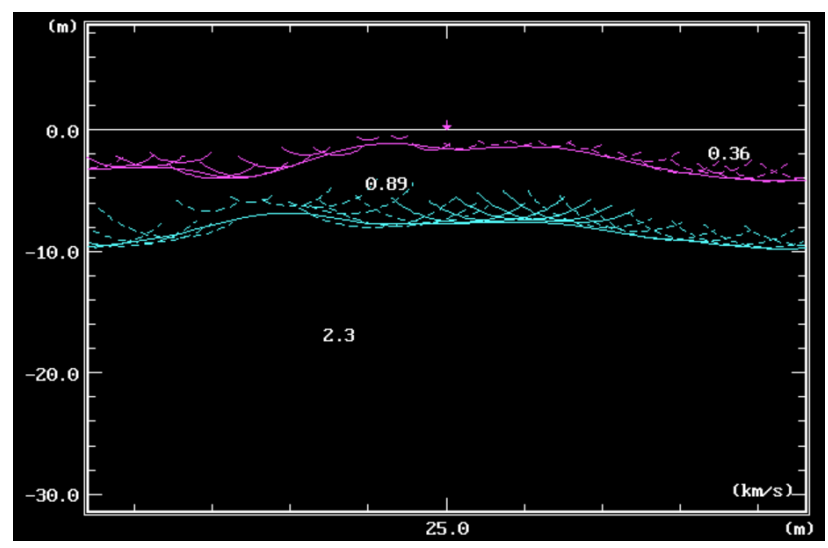

Gambar 5. H asil pencitraan struktur bawah permukaan

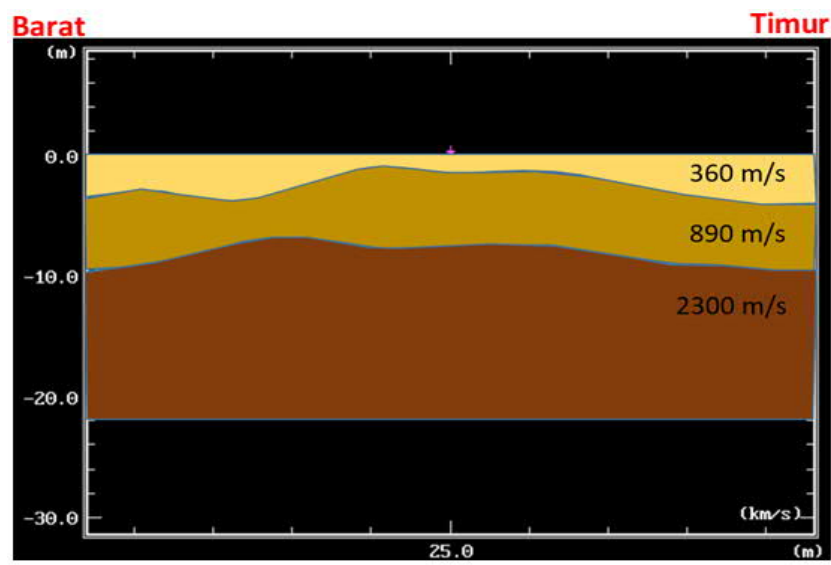

Gambar 6. M odel bawah permukaan

$\mathrm{H}$ asil interpretasi secara keseluruhan, maka lapisan akuifer yang sangat prospek berada pada batuan sedimen lempung tersaturasi. Batuan tersebut berada pada kedalaman lebih dari 12 meter. Model geologi bawah permukaan dapat dilihat pada Gambar 9.

\section{KESIMPULAN DAN SARAN}

Adapun kesimpulan pada penelitian ini bahwa lapisan akuifer di perumahan subsidi Green Jatimulyo 2, Desa Jatimulyo, Kecamatan
Jati Agung, Kabupaten Lampung Selatan, berada pada lapisan ketiga yang merupakan batuan sedimen lempung tersaturasi dengan kedalaman lebih dari 12 meter. Prediksi lapisan akuifer dilakukan dengan menggunakan metode seismik refraksi dan data sebaran resisitivitas sebagai pelengkap.

Saran dari penelitian ini adalah penggunaan data dan lintasan yang lebih banyak, selain bisa memprediksi kedalaman akuifer, disarankan juga untuk memprediksi jenis dari lapisan 
akuifer apakah termasuk pada akuifer tertekan, diharapkan juga bisa menentukan arah dan bocor atau yang lainnya. Disamping itu, pola dari aliran akuifer tersebut.

Tabel 2. Nilai kecepatan gelombang seismik untuk setiap batuan (M avko dkk., 2009).

\begin{tabular}{lcccc}
\hline \multicolumn{1}{c}{ Type of formation } & $\begin{array}{c}\text { P wave } \\
\text { velocity }(\mathrm{m} / \mathrm{s})\end{array}$ & $\begin{array}{c}\text { S wave } \\
\text { velocity }(\mathrm{m} / \mathrm{s})\end{array}$ & $\begin{array}{c}\text { Density } \\
(\mathrm{g} / \mathrm{cm} 3)\end{array}$ & $\begin{array}{c}\text { Density of constituent } \\
\text { crystal }(\mathrm{g} / \mathrm{cm} 3)\end{array}$ \\
\hline Scree, vegetal soil & $300-700$ & $100-300$ & $1.7-2.4$ & - \\
Dry sands & $400-1200$ & $100-500$ & $1.5-1.7$ & 2.65 quartz \\
W et sands & $1500-2000$ & $400-600$ & $1.9-2.1$ & 2.65 quartz \\
Saturated shales and & $1100-2500$ & $200-800$ & $2.0-2.4$ & - \\
M arls & $2000-3000$ & $750-1500$ & $2.1-2.6$ & - \\
Saturated shale and sand & $1500-2200$ & $500-750$ & $2.1-2.4$ & - \\
Porous and saturated & $2000-3500$ & $800-1800$ & $2.1-2.4$ & 2.65 quartz \\
Limestones & $3500-6000$ & $2000-3300$ & $2.4-2.7$ & 2.71 calcite \\
Chalk & $2300-2600$ & $1100-1300$ & $1.8-3.1$ & 2.71 calcite \\
Salt & $4500-5500$ & $2500-3100$ & $2.1-2.3$ & 2.1 halite \\
Anhydrite & $4000-5500$ & $2200-3100$ & $2.9-3.0$ & - \\
Dolomite & $3500-6500$ & $1900-3600$ & $2.5-2.9$ & $($ Ca, M g) Co 32.8-2.9 \\
Granite & $4500-6000$ & $2500-3300$ & $2.5-2.7$ & - \\
Basalt & $5000-6000$ & $2800-3400$ & $2.7-3.1$ & - \\
Gneiss & $4400-5200$ & $2700-3200$ & $2.5-2.7$ & - \\
Coal & $2200-2700$ & $1000-1400$ & $1.3-1.8$ & - \\
Water & $1450-1500$ & - & 1 & - \\
Ice & $3400-3800$ & $1700-1900$ & 0.9 & - \\
Oil & $1200-1250$ & - & $0.6-0.9$ & -
\end{tabular}

Tabel 3. Nilai resistivitas pada batuan (Saad dkk., 2012).

\begin{tabular}{ccc}
\hline M aterial & Resistivity (ohm-m) & Remark \\
\hline Sand & $81-257$ & \\
Saturated Sand & $45-75$ & W ater pumping rate, $\left.>10.8 \mathrm{~m}^{3} / \mathrm{h}\right)$ \\
Silty Sand & $29-57$ & \\
Clay & $37-88$ & \\
Silty Clay & $20-69$ & \\
Sandy Clay & $57-109$ & \\
Saturated sandy Clay & $37-39$ & W ater pumping rate, $\left.>10.8 \mathrm{~m}^{3} / \mathrm{h}\right)$ \\
Silty Clay with Sand & $20-97$ & W ater pumping rate, $\left.>10.8 \mathrm{~m}^{3} / \mathrm{h}\right)$ \\
Saturated Silty Clay with Sand & $31-45$ & \\
Soft Sedimentary rock & $54-56$ &
\end{tabular}




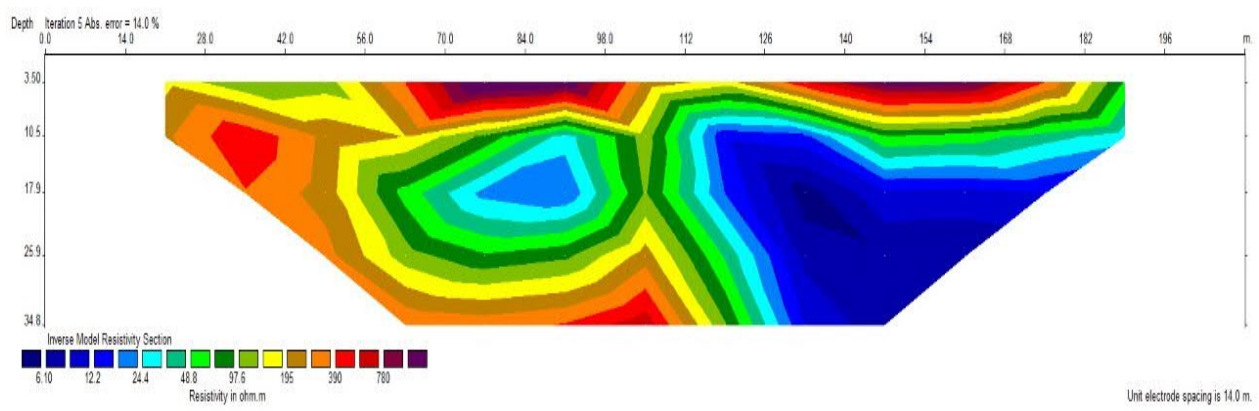

Gambar 7. Penampang tomografi resistivitas hasil pengolahan data geolistrik

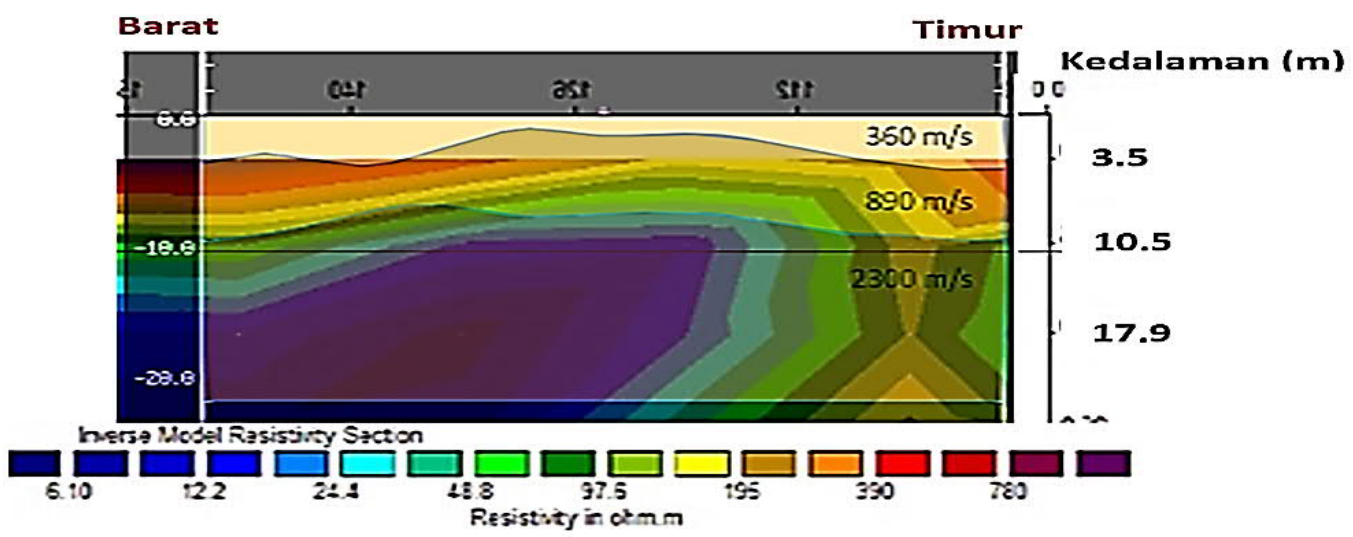

Gambar 8. Integrasi penampang kecepatan dengan penampang tomografi resistivitas

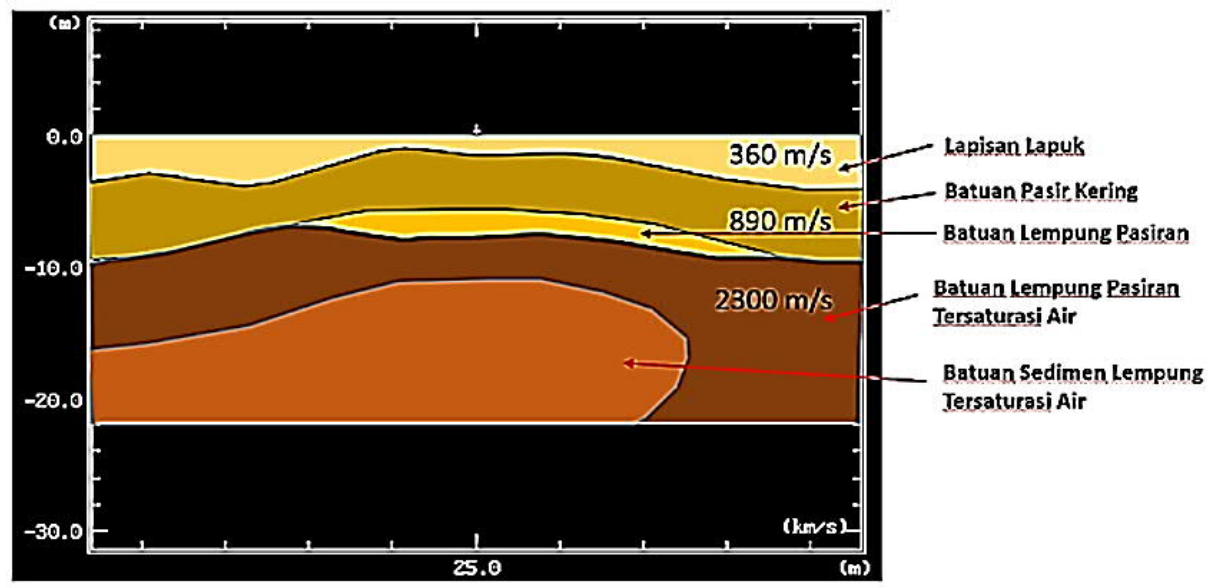

Gambar 9. M odel geologi bawah permukaan

\section{UCAPAN TERIMA KASIH}

U capan terima kasih kepada Bapak Kepala Desa dan masyarakat Desa Jatimulyo, Kecamatan Jati Agung, Kabupaten Lampung Selatan serta semua pihak yang turut berkontribusi dalam penelitian ini.

\section{DAFT AR PUSTAKA}

Ali, N., Saad, R., Saidin, M. M., \& Nordiana, M. M. (2012). A pplying Seismic Refraction Method in
Depicting Geological Contact. International Conference on Geological and Environmental Sciences, 36, 59-63.

Hudha, S. N., Harmoko, U., Widada, S., Y usuf, D. H., \& Yulianto, G. (2014). M enggunakan M etode Seismik Refraksi Di Lapangan Panas Bumi Diwak Dan Derekan , Kecamatan Bergas ,. 3(3), 263-268.

Listiyani, F., Nurwidyanto, M. I., \& Yuliyanto, G. (2006). Penentuan Kedalaman Dan Ketebalan Akuifer Menggunakan Metode Seismik Bias 
(Studi Kasus Endapan Alluvial Daerah Sioux Park, Rapid Creek, South Dakota, U nited State of America). Berkala Fisika, 9(3), 109-113-113.

M avko, G., M ukerji, T., \& Dvorkin, J. (2009). The Rock Physics Handbook. In The Rock Physics Handbook. Cambridge University Press. https://doi.org/10.1017/CB0 9780511626753

Nurdiyanto, B., Hartanto, E., N gadmanto, D., Sunardi, B., \& Susilanto, P. (2011). Penentuan Tingkat Kekerasan Batuan M enggunakan Metode Seismik Refraksi. Jurnal Meteorologi dan Geofisika. https://doi.org/10.31172/jmg.v12i3.103

Raharjo, S. A. (2002). Analisis Kecepatan Perambatan Gelombang Bias pada M edium dan Faktor Kualitas Medium di Lereng Barat Gunung Merapi. Skripsi S-1 Universitas Gajah Mada.
Refrizon, Suwarsono, \& Natalia, K. (2009). Visualisasi Struktur Bawah Permukaan dengan $M$ etode $\mathrm{H}$ agiwara. Jurnal Gradien.

Saad, R., Nawawi, M. N. M., \& M ohamad, E. T. (2012). Groundwater detection in alluvium using 2-D electrical resistivity tomography (ERT). Electronic Journal of Geotechnical Engineering.

Sri, U., \& Supriyadi. (2014). Identifikasi Potensi Longsor Menggunakan Metode Seismik Refraksi Di Kawasan Wisata Nglimut Desa Gonoharjo Limbangan Kendal. Unnes Physics Journal, 3(2).

Telford, W. M., Geldart, L. P., \& Sheriff, R. E. (1990). Applied geophysics. 2nd edition. Cambridge U niversity Press. 